\title{
MRI Evaluation of Central Nervous System in Childhood Developmental Delay
}

\author{
Abhishek S ${ }^{\circledR 1}$, Bhautik Kapadia ${ }^{2}$ \\ ${ }^{1}$ Assistant professor, Department of Radiodiagnosis, K.V.G Medical College and Hospital, Sullia, D K, Karnataka, India, ${ }^{2}$ Associate professor, Department of \\ Radiodiagnosis, Sir Sayajirao General Hospital and Medical College, Vadodara, Gujarat, India.
}

\section{Abstract}

Background: Developmental delay is defined as significant delay (more than two standard deviations below the mean) in one or more developmental domains. Developmental delay does not represent a diagnosis, but a term used in different clinical presentations and prognosis, which covers a wide range of etiologies including genetic, metabolic, endocrine, vascular, mal formation syndromes, traumatic, infections, toxins \& environmental causes. Careful evaluation and investigation can reveal a cause. The aim of our study to observe efficacy of MRI brain in children with developmental delay and to categories it's various causes. Subjects and Methods: Record based cross sectional study was done in 200 children, who presented to department of pediatrics with developmental delay and subsequently underwent MRI study. Results: Out of 200 patients $145(72.5 \%)$ shows abnormal MRI findings. Most common MRI diagnosis of developmental delay was neurovascular insult (29.5\%) followed by structural malformation (21\%), infective/inflammatory disorder (17\%), metabolic disorders $(2.5 \%)$ and neoplastic (2.5\%). Neurovascular insult was commonly found in 1-5 years of age. Conclusion: MRI is the most useful investigation in patients clinically suspicious for developmental delay and can help in diagnosing the underlying etiology. Other than no of lesions and predominant localization of lesions, encephalomalacia, gliosis, atrophy, structural malformations and neoplastic lesions, ventriculomegaly, micro or megalencephaly are useful features to diagnose underlying cause of developmental delay.

Keywords: MRI, children, Developmental delay

Corresponding Author: Bhautik Kapadia, Associate professor, Department of Radiodiagnosis, Sir Sayajirao General Hospital and Medical College, Vadodara, Gujarat, India.

E-mail: drbhautikkapadia@gmail.com

Received: 13 December 2019

Revised: 01 January 2020

Accepted: 23 January 2020

Published: 29 April 2020

\section{Introduction}

Development is a continuous process which begins from conception and continues up till maturity. However, during this process several factors like genetic, environmental, nutritional and chronic diseases can have adverse effects of delay in milestone which can be evaluated using four domains of gross motor, fine motor and social and language skills. ${ }^{[1]}$ Developmental delay is defined as significant delay (more than two standard deviations below the mean) in one or more developmental domains. ${ }^{[2]}$ Though no accurate records are available, it is believed that patients presenting with development delay constitute nearly $50 \%$ of patients presenting as out patients at various medical centers. ${ }^{[3]}$ Developmental delay may become evident during infancy or early childhood but becomes more apparent $\&$ therefore more often diagnosed in early school years. ${ }^{[4]}$
Developmental delay does not represent a diagnosis, but a term used in different clinical presentations and prognosis, which covers a wide range of etiologies including genetic, metabolic, endocrine, vascular, mal formation syndromes, traumatic, infections, toxins \& environmental causes. ${ }^{[1,5]}$ Careful evaluation and investigation can reveal a cause in 55$85 \%$ cases with developmental delay. ${ }^{[1,3,6]}$ This wide variation could be attributed to patient selection criteria where high proportions are reported; Some of the reported abnormalities are in children where diagnosis would be obvious clinically. The yield of useful diagnostic abnormalities is higher (more than $60 \%$ ) using newer techniques and in a population selected for developmental delay with clinical features.

Brain MRI is one of the major investigation of these patients, and based on previous studies, about $60 \%$ of cases have abnormal brain MRI. ${ }^{[1,2]}$ A complete study will provide important information about the patient, the rate and type of brain abnormalities. It helps to identify these diseases 
and their prognosis, preventing the recurrence and parent counseling. The present study was undertaken prospectively in 200 consecutive patients presenting to the Pediatric OPD of a tertiary hospital for evaluation of developmental delay. Radiological observations with specific reference to MRI study were made along with a review of literature.

This study provides a systematic approach to the causes of developmental delay and the importance of its rigorous investigation. It particularly highlights practical aspects relevant to neurological practice.

\section{Subjects and Methods}

This study is record based cross sectional in nature and was done in department of Radiodiagnosis in sir sayajirao general hospital and medical college- Vadodara it includes MRI findings of children with developmental delay. Institutional ethics committee has approved the study and informed consent was taken from parents.

All the patients from birth to $\leq 12$ years presenting with developmental delay to Pediatric Department and referred for neuro-imaging were recruited for the study.

A detailed history were obtained from these patients and MRI brain study was performed with a GE medical system, 1.5T MRI machine using standard head coil for acquisition of image. Data were analyzed and Patients were categorized based on age group, anatomical structures involved and etiology as Traumatic/ Neurovascular Diseases, Congenital \& Developmental, Metabolic and Degenerative, neoplastic and non-specific.

\section{Results}

In the study total 200 children with developmental delay were enrolled. Among them 115 were males and 85 were females. Patients were divided into seven age groups: up to 6 months, 6-12 months, 1-3 years, 3-5 years, 5-7 years, 7-9 years, and 912 years. Maximum number of abnormalities were detected in age group of 5 to 7 years in $26 \%$ of children, followed by 3 to 5 years age in $21.5 \%$ of children.

Out of 200 children 145 (72.5\%) had abnormal MRI findings and $55(27.5 \%)$ has normal MRI brain. Abnormal MRI findings were comparatively more common in the children with seizures. Most common involved lobe is parietal lobe (33\%) followed by frontal (16\%) and occipital lobe (11\%).

Brain MRI findings were categorized into the following groups:

\section{- Normal}

- Neurovascular diseases like hypoxic ischemic injury and non-specific findings: Encephalomalacia, gliosis, hypoplasia of corpus callosum, ventriculomegaly.

- Infectious and inflammatory injury.

- Structural malformations- corpus callosum agenesis, heterotopias, Chiari malformations, Dandy walker malformation, Lissencephaly, schizencephaly and microcephaly.

- Metabolic diseases.

- Neoplastic etiology.

The most common MRI diagnosis of developmental delay was neurovascular insult to the brain found in 59 (29.5\%) cases. Most common age group involved was between 1-5 yrs. to present with developmental delay. MRI findings were consistently associated with changes of encephalomalacia in 18 patients (30.5\%), atrophy or volume loss and gliosis with ex-vacuo dilatation of ventricles was noted in the 27 patients (45.76\%), thinning of corpus callosum in 3 patients $(5 \%)$, and gliosis in 4 patients (6.7\%). Many patients presented with overlapping findings.

The second most common MRI diagnosis of developmental delay was structural malformation of brain found in 42 cases. Most common age group involved was between 3-7 yrs. Most common malformation was chiari-II (19\%), followed by dandy walker malformation (14.2\%), and followed by microcephaly (12\%).

The third most common MRI diagnosis of developmental delay was the infective and inflammatory causes resulted in developmental delay in 34 patients (17\%) with Predominate age group involved was noted between the 5-9 yr. 24 patients had meningitis with bacterial and tuberculosis. 10 patients had post-acute encephalopathy or encephalitis sequel. Few were post infective vasculitic infarcts and brain insults, abscesses.

Fourth most diagnosis of developmental delay was metabolic etiology. 5 patients $(2.5 \%)$ out of which 2 patients had Adrenoluecodystrophy, 2 patients had hyperbilirubinemia and 1 patient of Dysmyelination.

5 cases were diagnosed as neoplastic causes of developmental delay. 2 cases of Craniopharyngioma, 1 case of glioma, 1 case of ependymoma, 1 case of dural metastasis from leukemia.

\section{Discussion}

Evaluation of developmental delay was done in 200 pediatric patients of age group of up to 12 years referred for MRI from our Pediatric OPD. The proportions of children having abnormal MRI findings in our study of 145 cases could get a definitive diagnostic yield of $72.5 \%$ ( 145 cases).

Similar yield of MRI has been reported by Momen et al. ${ }^{[1]}$, Shevell et al. ${ }^{[3]}$, Pandey et al., ${ }^{[6]}$ Koul et al., ${ }^{[7]}$ Battaglia et al., ${ }^{[2]}$ and Widjaja et al., ${ }^{[8]}$ who had a yield of $58.6 \%$, $65.5 \%, 63.8 \%, 71.8 \%, 80.8$ and $84 \%$ respectively. Wide range 


\begin{tabular}{|lll}
\hline \multicolumn{2}{l}{ Table 1: Age wise distribution } \\
\hline Age group & No. of patients & $\%$ of patients \\
\hline 0-6 months & 12 & 06 \\
\hline 6-12 months & 14 & 07 \\
1-3years & 33 & 16.5 \\
3-5years & 43 & 21.5 \\
\hline 5-7years & 52 & 26 \\
7-9years & 32 & 16 \\
9-12years & 14 & 07 \\
\hline Total & 200 & $100 \%$ \\
\hline
\end{tabular}

Table 2: Etiology wise distribution abnormality in developmental delay patients

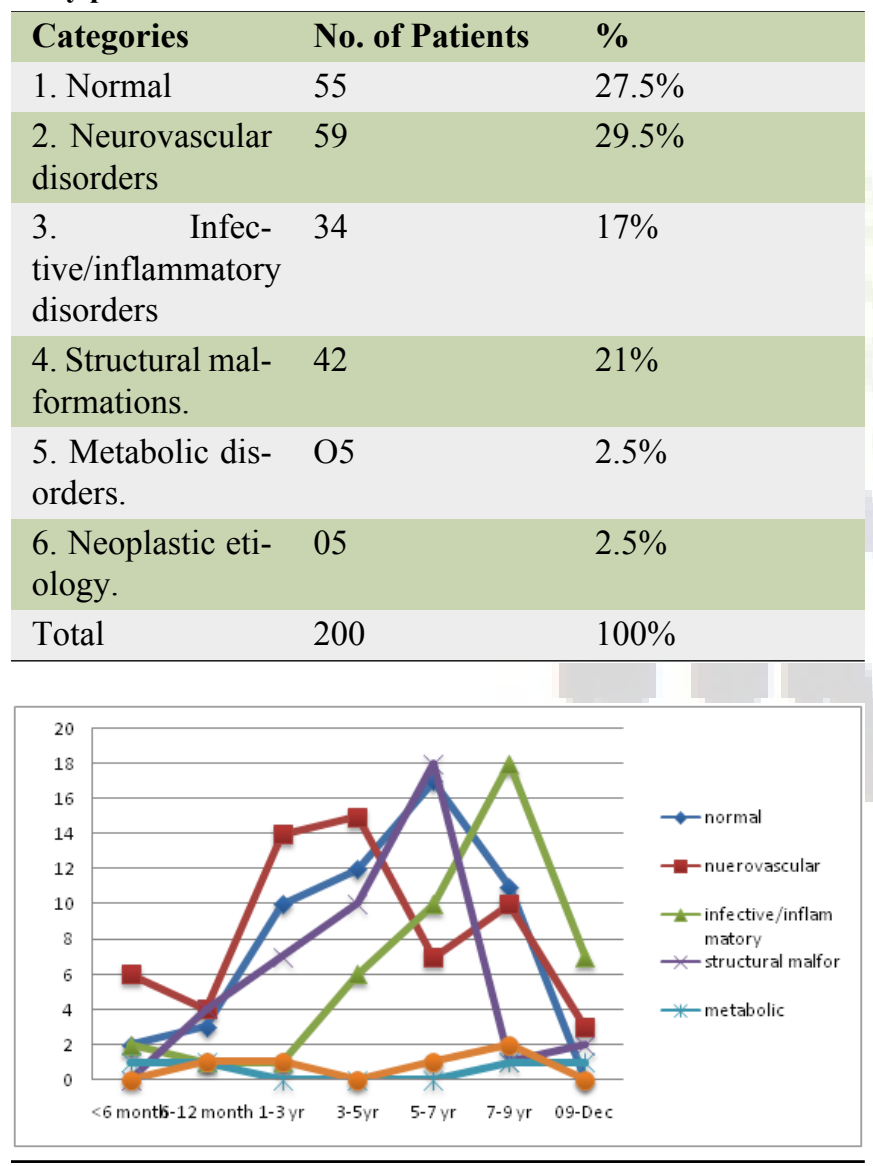

Graph 1: Distribution of abnormalities as per common MRI diagnosis in different age groups $(\mathrm{N}=\mathbf{2 0 0})$

of such yield could be due to the patient selection criteria and awareness about investigating such children in different population group.

Most of the children with abnormal MRI findings in our study were in age group of 5-7 yrs (26.5\%) with the next peak at 3-5

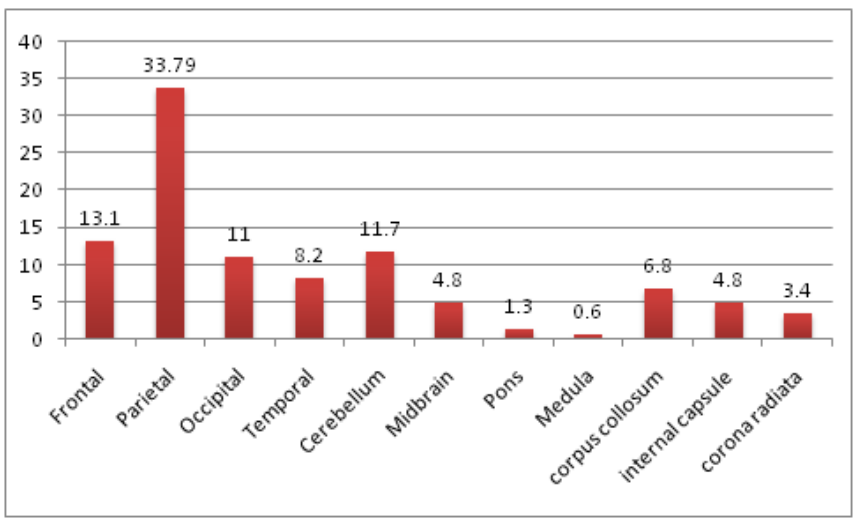

Graph 2: Distribution of abnormalities on the basis of predominant localization in different parts of brain as per MRI diagnosis.

Table 3: Comparison between the present study and other studies showing yield of abnormal MRI findings

\begin{tabular}{|ll}
\hline Studies & $\begin{array}{l}\text { Abnormal } \\
\text { (in \%) }\end{array}$ \\
\hline Present study & $72.5 \%$ \\
\hline Arul Dasan et al., ${ }^{[9]}$ & $72 \%$ \\
\hline Momen et al., ${ }^{[1]}$ & $58.6 \%$ \\
\hline Ali AS et al., ${ }^{[10]}$ & $68 \%$ \\
\hline Kouletal., ${ }^{7]}$ & $71.8 \%$ \\
\hline Widjaja et al. ${ }^{[8]}$ & $84 \%$ \\
\hline Bouhadiba et al., ${ }^{[11]}$ & $48.6 \%$ \\
\hline
\end{tabular}

Table 4: Age D istribution

\begin{tabular}{lll}
$\begin{array}{l}\text { Arul dasan et } \\
\text { al. }{ }^{[9]}\end{array}$ & Ali AS et al. ${ }^{[10]}$ & Present study. \\
\hline $9-12$ yrs & 3 month-1 yrs & $5-7$ yrs \\
\hline
\end{tabular}

\& 7-9 yrs (21.5\%) respectively. Males (57.5\%) were slightly more in number than females $(42.5 \%)$ although there is no considerable difference. Similar age of presentation and sex incidence was noted in the study performed by Arul Dasan et al. ${ }^{[9]}$

The 145 cases with abnormal MRI were evaluated for involvement of various anatomical structures. Abnormalities of ventricles and White matter in the parietal lobe was the most common followed by occipital lobe; Seen in $29.5 \%$ and $17.5 \%$ cases respectively. Arul Dasan et al., ${ }^{[9]}$ studied 90 such children and found parietal-occipital lobe involvements were common.

Most of the patients with abnormal brain MR had findings that could be classified as group II ( $40.6 \%$ of all children) 


\begin{tabular}{|c|c|c|c|}
\hline $\begin{array}{l}\text { Arul dasan } \\
\text { et al. }{ }^{[9]}\end{array}$ & $\begin{array}{l}\text { Ali AS et } \\
\text { al. }\end{array}$ & $\begin{array}{l}\text { Widjaja } \\
\text { et al. }\end{array}$ & $\begin{array}{l}\text { Present } \\
\text { study. }\end{array}$ \\
\hline $\begin{array}{l}\text { Parieto- } \\
\text { occipital } \\
\text { lobe }(34 \%)\end{array}$ & $\begin{array}{l}\text { Ventricular } \\
\text { system } \\
(61.8 \%) \\
\text { followed } \\
\text { by white } \\
\text { matter } \\
(58.2 \%)\end{array}$ & $\begin{array}{l}\text { Ventricle } \\
\text { and corpous } \\
\text { callosum }\end{array}$ & $\begin{array}{l}\text { Parietal lobe } \\
\& \text { ventricles } \\
(29.5 \%)\end{array}$ \\
\hline
\end{tabular}

Table 6: Neurovascular insult

\begin{tabular}{lllll}
\hline $\begin{array}{l}\text { Neurovasc } \\
\text { insult }\end{array}$ & $\begin{array}{l}\text { Arul } \\
\text { dasan et } \\
\text { al. }{ }^{[9]}\end{array}$ & $\begin{array}{l}\text { Ali AS et } \\
\text { al. }{ }^{[10]}\end{array}$ & $\begin{array}{l}\text { Momen } \\
\text { et al. }{ }^{[1]}\end{array}$ & $\begin{array}{l}\text { Present } \\
\text { study. }\end{array}$ \\
\hline Percentage & $58.8 \%$ & $31.1 \%$ & $25 \%$ & $29.5 \%$ \\
\hline
\end{tabular}

Table 7: Structural malformation

\begin{tabular}{lllll}
\hline $\begin{array}{l}\text { Structura] } \\
\text { malfor- } \\
\text { mation }\end{array}$ & $\begin{array}{l}\text { Arul } \\
\text { dasan } \\
\text { et al. }{ }^{[9]}\end{array}$ & $\begin{array}{l}\text { Ali AS et } \\
\text { al. }{ }^{10]}\end{array}$ & $\begin{array}{l}\text { Momen } \\
\text { et al. }{ }^{[1]}\end{array}$ & $\begin{array}{l}\text { Present } \\
\text { study. }\end{array}$ \\
\hline $\begin{array}{l}\text { Percentage } \\
11.1 \%\end{array}$ & $17 \%$ & $12 \%$ & $21 \%$ \\
\hline
\end{tabular}

Table 8: Metabolic Changes

\begin{tabular}{llll}
\hline Metabolic & $\begin{array}{l}\text { Arul dasan } \\
\text { et al. [9] }\end{array}$ & $\begin{array}{l}\text { Ali AS et } \\
\text { al. }{ }^{[10]}\end{array}$ & $\begin{array}{l}\text { Present } \\
\text { study. }\end{array}$ \\
\hline Percentage & $1.1 \%$ & $10 \%$ & $2.5 \%$ \\
\hline
\end{tabular}

- which included non-specific findings and neurovascular sequelae to ischemic insult. Also, a wide variety of congenital malformations/ cerebral dysgenetic disorders and recognizable neurodegenerative diseases of the brain can also lead to delayed development. These are demonstrable on brain MRI.

Second most of the patients with abnormal brain MR had findings that could be classified as group IV (21\% of all children) - structural malformation. Most common age group involved between 5-7yrs with commoner diagnosis of chairiII, Dandy walker malformation and microcephaly of $19 \%$, $14 \% \& 12 \%$ respectively.

The congenital and Developmental Anomalies have distinctive clinical and radiological findings, and their identification is very important in order to prevent recurrence and helps in parent counseling. ${ }^{[12]}$ We have found 42 such cases $(21 \%)$; which fit into this category;

The present study had five cases included in metabolic subgroup; Of which one case of hyperbilrubenimia induced insult to the basal ganglia, one of neurofibromatosis-I, two cases of dysmyelination and 2 cases were of adrenoleucodystrophies.

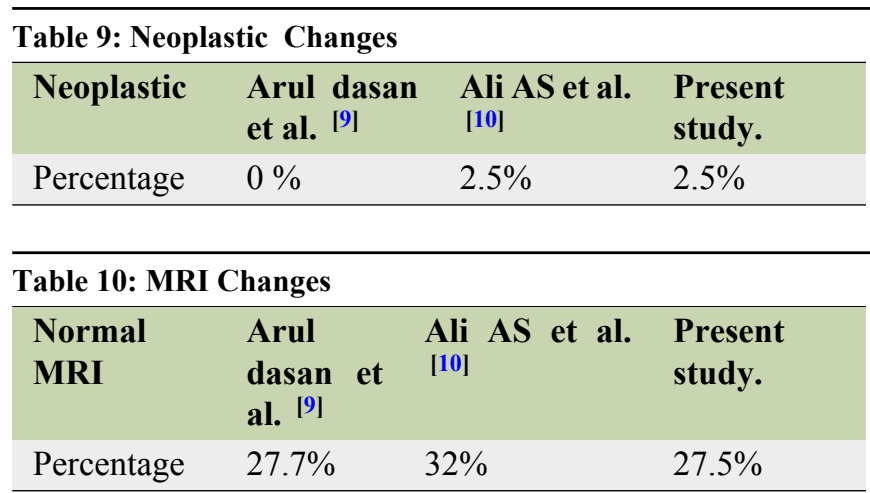

Five cases presenting with developmental delay had neoplastic origin. cases were 2 patients had Craniopharyngioma, 1 patient with glioma, 1 patient ependymoma, 1 patient with dural metastasis from leukemia. Maw et al., ${ }^{[12]}$ also observed similar incidence of Metabolic/Neoplastic Diseases causing developmental delay. ${ }^{[13-15]}$

\section{Cases}
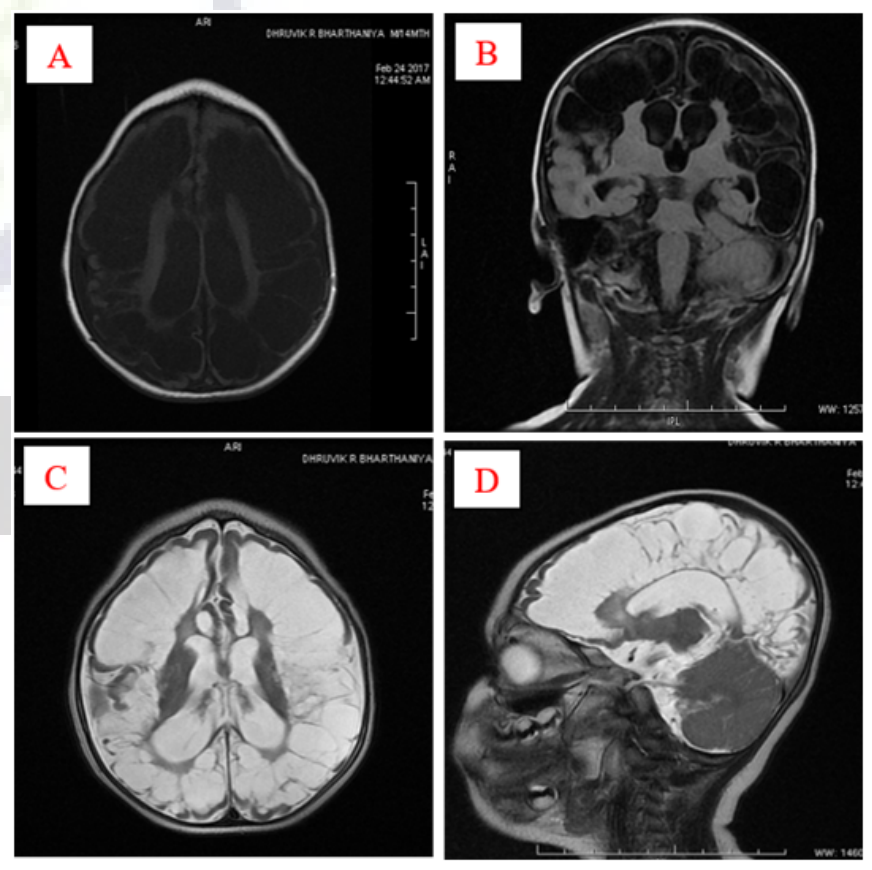

Figure 1: Case of Hypoxic ischemic encephalopathy: (A) axial T1 weighted, (B) coronal FLAIR. (C,D) axial and sagittal T2 weighted MR images showing multifocal periventricular small and large cystic lesions of white matter- bilateral fronto-temporo-parieto-occipital lobes with dilatation of adjacent ventricles. Thinning of corpus callosum.

The frequency of normal brain MRI was higher in among all the age groups $(21.5 \%)$, whereas the frequency of abnormal 


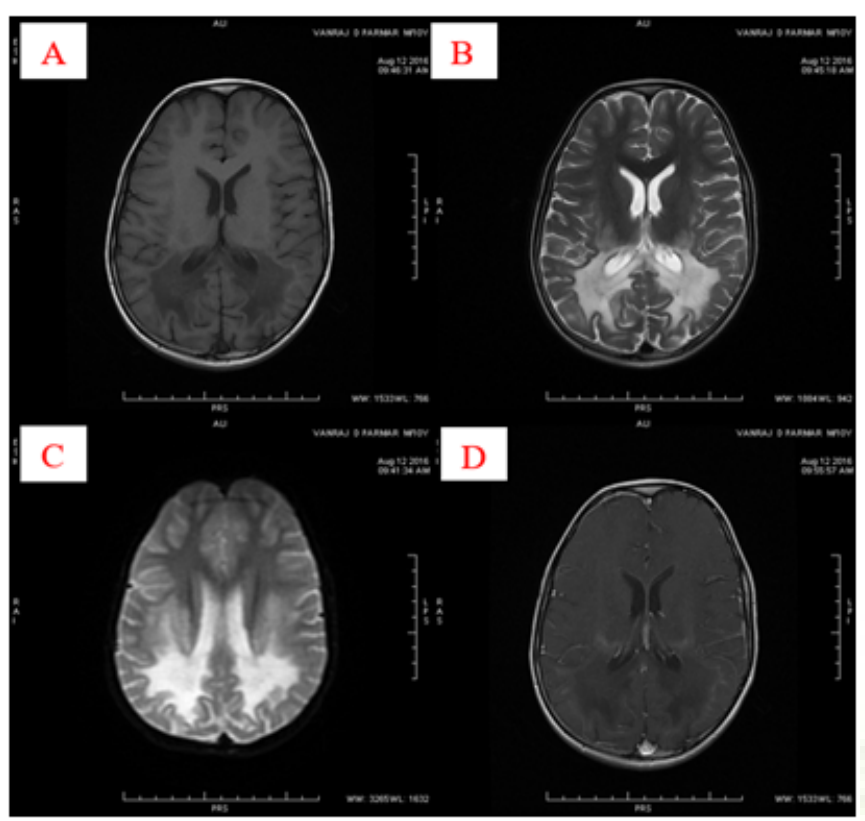

Figure 2: Case of Adrenoleukodystrophy- 10 years old child with progressive impairment motorand cognitive function, vision and hearing. (A) Axial T1 (B) axial T2 (C) axialdiffusion (D) axial T1 weighted post contrast MR images showing abnormal signal intensitylesion involving the bilateral trigonal region and occipital region givingrestricted diffusion in the outer aspect with post contrast enhancement on theleading edge of the lesions.

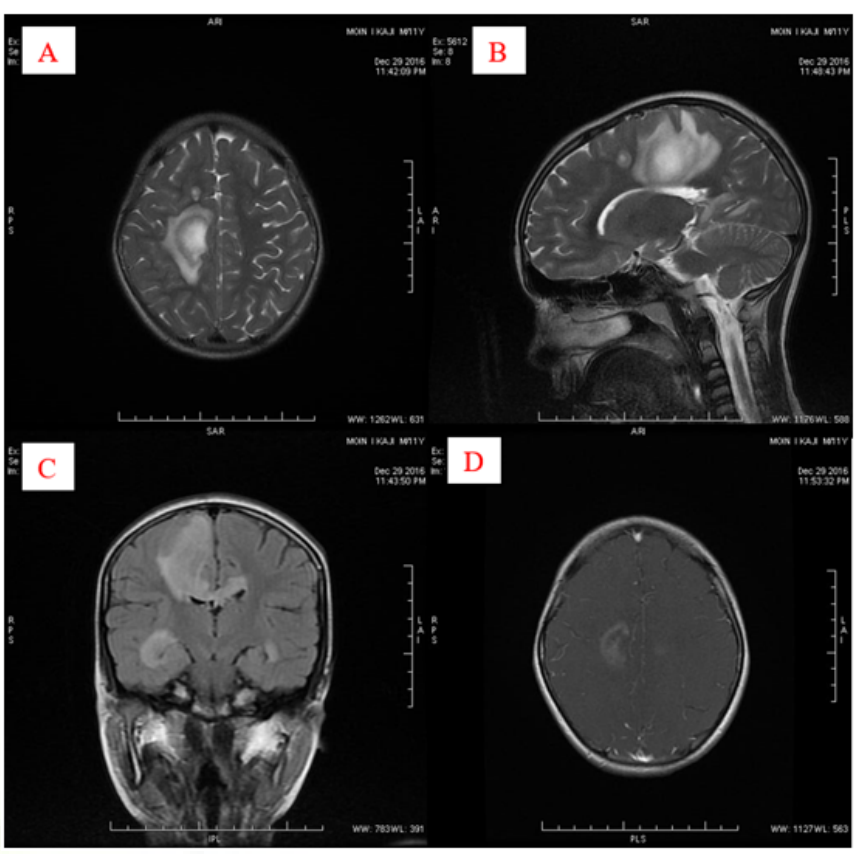

Figure 4: Case of acute disseminated encephalomyelitis6 year female patient presented with bilateral vision loss, ataxia, and with rigidity. (A,B) axial and sagittal T2 weighted, (C) coronal FLAIR and (D) axial T1 weighted post contrast images showing Multifocal small poorly defined abnormal signal intensity lesions showing incomplete peripheral rim - mildly hypointense on T2W \& FLAIR images extending into posterior body of corpus callosum and bilateral peritrigonal white matter and white matter along bilateral temporal lobes. They show thick peripheral curvilinear and incomplete rim like enhancement along ependymal margin. They show mild to moderate perilesionaloedema. Partial effacement of adjacent ventricles.

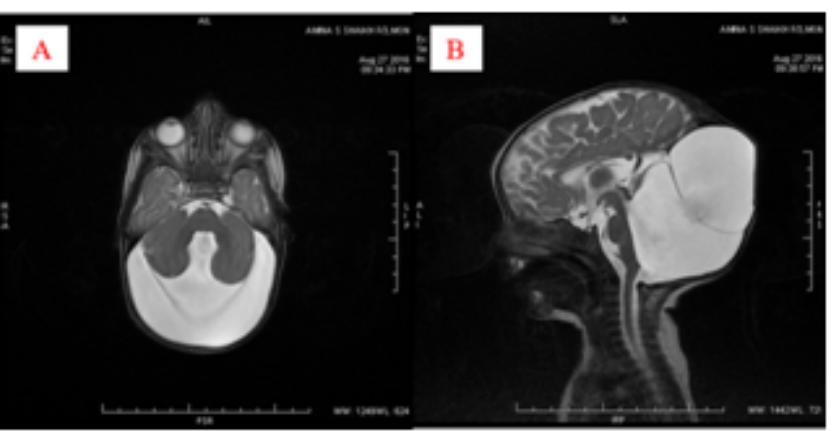

Figure 5: Case of dandy walker malformation- (A,B) axial and sagittal T2 weighted MR images showing hypoplasia of cerebellar vermis and cephalad rotation of vermian remnant. Cystic dilatation of fourth ventricle extending posteriorly. Enlarged posterior fossa with torcula-lambdoid inversion. 


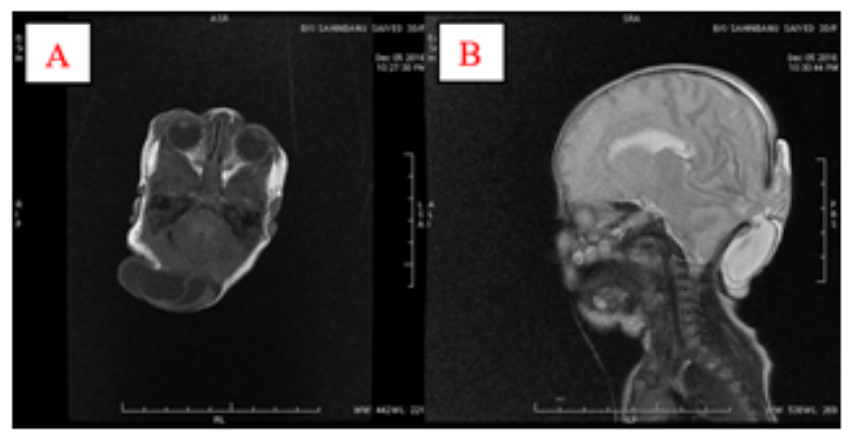

Figure 6: Arnold chiary-III malformation- (A) axial T1 and (B) sagittal T2 weighted MR images showing large defect in the occipital bone with dysplastic cerebellum and herniation of meninges and cerebellum.

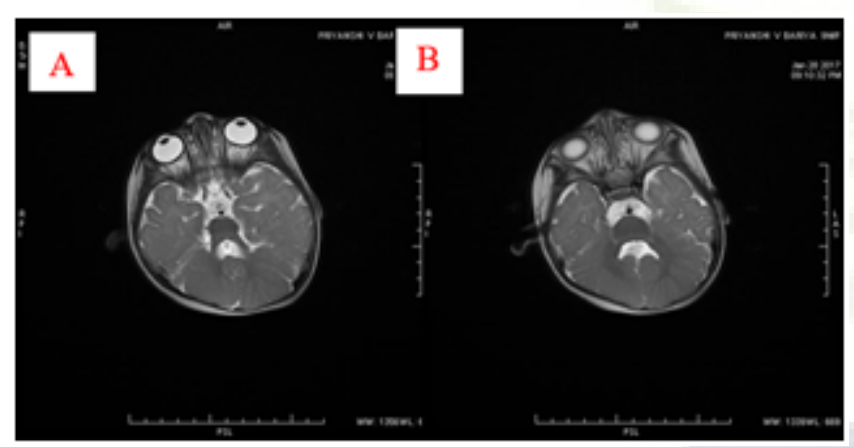

Figure 7: Case of joubert syndrome- (A,B) axial T2 weighted MR image at the level of superior cerebellar peduncle and pons showing narrow superior cerebellar peduncles giving "Molar tooth" appearance Small dysplastic vermis. $4^{\text {th }}$ ventricle has bat wing appearance.

brain MRI was found to be the highest in the age group 3 yrs-9 years (44-48.8\%). This is probably because children with developmental delay are identified and evaluated more frequently when they are older between 3-9 yrs as our hospital is the tertiary referral center and many of the patient were born in the periphery of the state with lack of sophisticated facility and care and they are identified late and investigated later after the referral to our center. ${ }^{[16-18]}$

No gender significant difference was observed between normal and abnormal brain MRI.

No significant association was found with history of seizure disorder/complications in the neonatal period with abnormal brain MRI this finding correlates with Aruldasan et al. ${ }^{[9]}$ Andali AS et al. ${ }^{[10]}$

The main drawback of the present study was developmental delay children's were not identified and not investigated at

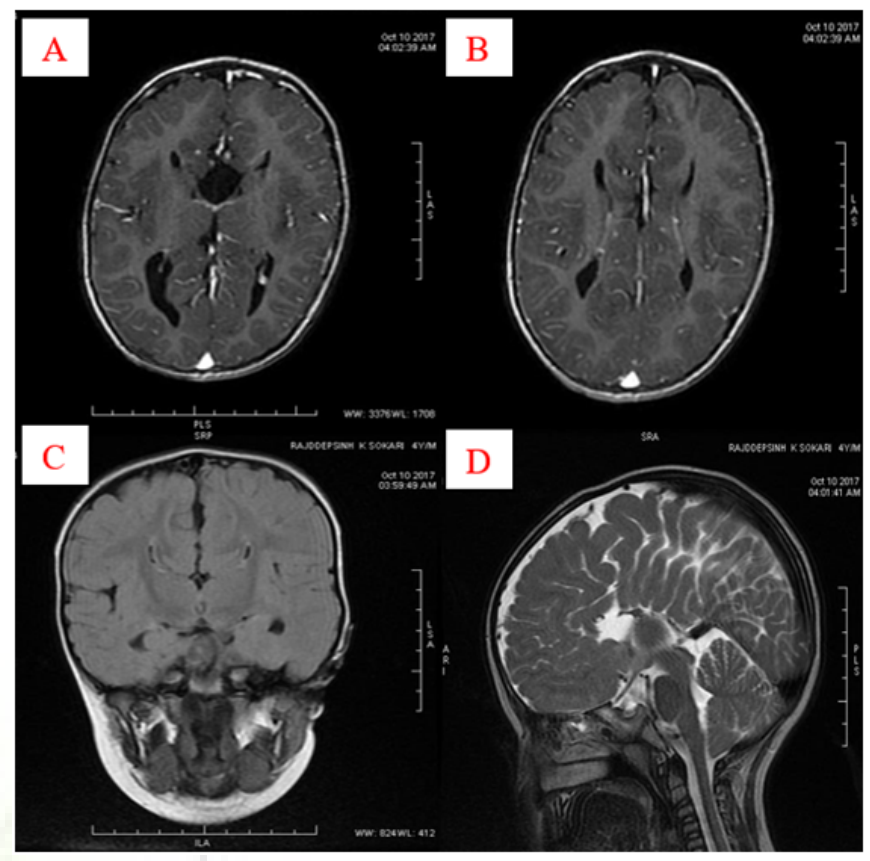

Figure 8: Case of corpus callosum agenesis- $(\mathrm{A}, \mathrm{B})$ axial T1 weighted post contrast (C) coronal FLAIR and (D) mid-sagittal T2 weighted MR images- lateral ventricles are non convergent, widely separated and appear parallel to each other giving "racing car sign". Probst bundles are seen. Pointed upcurving bilateral lateral ventricles with high riding third ventricle giving a "Viking helmet or moose head appearance". Sagittal images shows nonvisualization of corpus callosum. Cingulate gyrus is absent with gyri appearing to radiate outward from the third ventricle. Occipital horns of bilateral lateral appears dilated (colpocephaly). Polymicrogyria noted in left frontal region.

the right time and most of the patients were referred from the peripheral centres which should have investigated earlier. Which leads to random presentation of different aetiologies at random age group and spurious association with wrong age group and many of the normal patients were lost to follow up and not entirely investigated. Also did not correlate our findings with abnormal electroencephalography. ${ }^{[19-21]}$

\section{Conclusion}

In our study, most common etiology for developmental delay was neurovascular disorders $(29.5 \%)$ followed by structural malformations $(21 \%)$. Third most common etiology was infective, inflammatory disorders (17\%). Less common etiologies were metabolic, neoplastic disorders.

In our study predominate localization of abnormality was noted involve parietal lobe (33\%) followed by frontal (16\%) 
and occipital lobe (11\%). Hypoxic ischemic encephalopathy showed bilateral asymmetrical involvement of bilateral lobes in cortical \& subcortical region with basal ganglia involvement. Some cases had of HIE had bilateral symmetrical diffuse involvement of deep\& periventricular white matter.

Infective inflammatory etiology (17\%). Many patients had meningitis \&menindoencephalopathy in the past with pyogenic was than tubercular \& viral. Post infective/inflammatory demylinating disorder, post infective vasculitic infarcts and brain insults and abscesses. Hydrocephalus (communicating and non-communicating hydrocephalus), encephalomalacia, brain atrophy and gliosis were consistent findings. Among the non-communicating hydrocephalus aqueduct stenosis was seen in significant patients.

The imaging features of various disease described in literature are largely reliable for diagnosis in significant number cases studied by us. They can be confidently referred to for making an accurate or near accurate diagnosis in $72.5 \%$.

We conclude from our study that MRI is the most useful investigation in patients clinically suspicious for developmental delay and can help in diagnosing the underlying etiology. Other than no of lesions and predominant localization of lesions, encephalomalacia, gliosis, atrophy, structural malformations and neoplaticlesions, ventriculomegaly, micro or megalencephaly are useful features to diagnose underlying cause of developmental delay.

\section{References}

1. Momen AA, Jelodar G, Dehdashti H. Brain Magnetic Resonance Imaging Findings in Developmentally Delayed Children. Int J Pediatr. 2011;2011:1-4. Available from: https: //dx.doi.org/10.1155/2011/386984.

2. Battaglia A, Carey JC. Diagnostic evaluation of developmental delay/mental retardation: An overview. Am J Med Genet. 2003;117C(1):3-14. Available from: https://dx.doi.org/10. 1002/ajmg.c.10015.

3. Shevell M, Ashwal S, Donley D, Flint J, Gingold M, Hirtz $\mathrm{D}$, et al. Practice parameter: evaluation of the childwith global developmental delay: report of the quality standards subcommittee of the American Academy of Neurology. Neurol. 2003;60(3):367-80. Available from: https://doi.org/10.1212/ 01.wnl.0000031431.81555.16.

4. Mcdonald LA, Rennie AC. Investigating developmental delay / impairment. Paediatr Child Health. 2011;21(10):443-490. Available from: https://doi.org/10.1016/j.paed.2011.02.008.

5. Petersen MC, Kube DA, Palmer FB. Classification of developmental delays. Semin Pediatr Neurol. 1998;5(1):214. Available from: https://dx.doi.org/10.1016/s1071-9091(98) 80012-0.

6. Pandey A, Phadke SR, Gupta N, Phadke RV. Neuroimaging in mental retardation. Indian J Pediatr. 2004;71(3):203-209. Available from: https://doi.org/10.1007/bf02724269.
7. Koul R, Al-Yahmedy M, Al-Futaisi A. Evaluation children with global developmental delay: A prospectivestudy at sultan qaboos university hospital, oman. Oman Med J. 2012;27(4):310-313. Available from: https://dx.doi.org/10. 5001/omj.2012.76.

8. Widjaja E, Nilsson D, Blaser S, Raybaud C. White matter abnormalities in children with idiopathic developmental delay. Acta Radiol. 2008;49(5):589-595. Available from: https://dx. doi.org/10.1080/02841850801950087.

9. Dasan TA, Deepashree B. The Role of Brain Magnetic Resonance Imaging in the Evaluation of Children with Global Developmental Delay. Int J Anatomy Radiol Surg. 2004;22:123-128. Available from: https://dx.doi.org/10.7860/ IJARS/2016/20141.2140.

10. Ali AS, Syed NP, Murthy GSN, Nori M, Abkari A, Pooja BK, et al. Magnetic resonance imaging evaluation of developmental delay in pediatric patients. J Clin Diagn Res. 2015;9(1):21-24. Available from: https://dx.doi.org/10.7860/JCDR/2015/11921. 5478.

11. Bouhadiba Z, Dacher J, Monroc M, Vanhulle C, Menard J, Kalifa G. MRI of the brain in the evaluation of children with developmental delay. J de Radiologie. 2000;81(8):870-873.

12. Maw A. Paediatric Neurology - History and Examination. In: and others, editor. Adv Clin Neurosci Rehabilit . vol. 9 of 5; 2009. p. 34-40.

13. Battaglia A, Bianchini E, Carey JC. Diagnostic yield of the comprehensive assessment of developmental delay/mental retardation in an institute of child neuropsychiatry. Am J Med Genet. 1999;82(1):60-66. Available from: https://doi.org/10.1002/(SICI)1096-8628(19990101)82: 1\%3C60::AID-AJMG12\%3E3.0.CO;2-4.

14. Al-Naddaw M, Ibraheem MF, Alwa SH. Causes of Global Developmental Delay in Children Welfare Teaching HospitalBaghdad. Postgrad Med J. 2013;12(3):23-27.

15. Williams J. Global developmental delay - globally helpful. Dev Med Child Neurol. 2010;52(3):227-231. Available from: https://doi.org/10.1111/j.1469-8749.2010.03622.x.

16. Whiting K. Investigating the child with learning difficulty. Current Paediatr. 2001;11(4):240-247. Available from: https: //dx.doi.org/10.1054/cupe.2001.0195.

17. Oxford specialist handbook in paediatric neurology. In: Forsyth R, Newton R, et al., editors. Arch Dis Child. vol. 92 of 11. Oxford University Press; 2007. p. 1049.

18. Grainger RG, Allison DJ, Adam A, Dixon A. Diagnostic Radiology- A Textbook of Medical Imaging. 6th ed. and others, editor; 2015.

19. Walters AV. Developmental delay causes \& investigations. ACNR. 2010;10(2):32-34.

20. Tikaria A, Kabra M, Gupta N, Sapra S, Balakrishnan P, Gulati $\mathrm{S}$, et al. Aetiology of global developmental delay in young children: experience from tertiary care center in India. Natl Med J India. 2010;23(6):3249-3249.

21. Fayyazi A, Kheizrian L, Kheradmand Z, Damadi S, Khajeh A. Evaluation of the young children with neurodevelopmental disability: a prospective study at Hamadan University of Medical Sciences Clinics. Iran J Child Neurol. 2013;7(1):2933. 
Copyright: (C) the author(s), 2020. It is an open-access article distributed under the terms of the Creative Commons Attribution License (CC BY 4.0), which permits authors to retain ownership of the copyright for their content, and allow anyone to download, reuse, reprint, modify, distribute and/or copy the content as long as the original authors and source are cited.

How to cite this article: Abhishek S, Kapadia B. MRI Evaluation of Central Nervous System in Childhood Developmental Delay. Asian J. Med. Radiol. Res. 2020;8(1):1-8.

DOI: dx.doi.org/10.47009/ajmrr.2020.8.1.1

Source of Support: Nil, Conflict of Interest: None declared. 